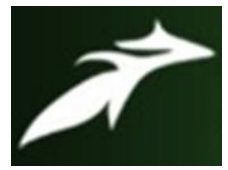

Pramila Tripathi et al, International Journal of Advances in Agricultural Science and Technology,

Vol.6 Issue.10, October-2019, pg. 62-71

ISSN: 2348-1358

Impact Factor: 6.057

NAAS Rating: 3.77

\title{
Assessment of in vitro Antifungal Prospective of Fungicides against Alternaria alternata, A Causal Organism of Potato Brown Spot and Early Blight Disease
}

\author{
Pramila Tripathi ${ }^{1}$; A.K. Shukla ${ }^{2}$ \\ ${ }^{1}$ Department of Botany, D.A.V-P.G. College, Kanpur- 208001 \\ ${ }^{2}$ Department of Botany, Indira Gandhi National Tribal University, Amarkantak- 484887
}

DOI: $\underline{10.47856 / i j a a s t .2019 . v 06 i 10.001}$

\begin{abstract}
Efficacy evaluation of three fungicides was undertaken against phytopathogenic fungi Alternaria alternata. Fungicide copper oxychloride was found to restrict the growth of fungi at 500ppm concentration, whereas at 5000ppm concentration of benomyl and mancozeb growth of fungi was not occurred. At $1000 \mathrm{ppm}$ concentration growth of fungi was fifty percent compare to control on PDA medium. At 5000ppm concentration of copper oxychloride and mancozeb spore germination did not occur. In case of both the fungicides at $1000 \mathrm{ppm}$ concentration percent germination was found between 56 and 75 percent. Germination percent of spores was always lesser than control in all the treatments. Similarly germ tube growth was not occurred in copper oxychloride and mancozeb treated spores at 5000ppm concentration. Germ tube growth was found always influenced by the treatment of fungicides. Inhibitory effect of fungicides was dose dependent and proportional to the concentration of fungicides. Reduction in growth, spore germination and germ tube elongation increased on increasing the concentration of fungicides.
\end{abstract}

\section{Introduction}

Alternaria alternata (Fr.) Keissler is one of the causes of brown leaf spot disease of potato, it generally effects on the above ground part causing a serious loss in the yield. The fungus was reported to cause black pit disease of potato tuber also. Alternaria alternata has been reported as a leaf pathogen on a number of other hosts which include crops and trees of immense economic value. Alternaria is considered one of the most diverse genera of plant pathogens. A. alternata has several pathotypes which cause number of diseases in other plants such as; stem canker of tomato (Grogan et al., 1975), Alternaria black spot of strawberry (Tsuge et al., 2011), leaf spot and fruit rot of chilli (Ginoya and Gohel, 2015), leaf spot of bean, black point of wheat (Cromey and Mulholland, 1988), stem rot of mango (Li et al.,2018), and Alternaria fruit rot of persimmon (Prusky et al., 1981). Early blight and brown spot, which 


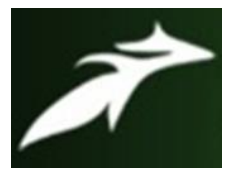

Pramila Tripathi et al, International Journal of Advances in Agricultural Science and Technology, Vol.6 Issue.10, October-2019, pg. 62-71

ISSN: 2348-1358

Impact Factor: 6.057

NAAS Rating: 3.77

were considered as the same disease by Leiminger and Hausladen, (2012) and Paurson et al., (2015), can damage potato foliage and tubers. Early blight can cause yield losses of 5- 50 \% (Tsedalye, 2014), and in some continents it reaches up to 73 \% (Kapsa, 2009). Early studies conducted by Tsedalye, (2014) revealed that among many diseases of potato, foliar diseases (i.e. early blight and/or brown spot) are the most important and destructive diseases worldwide, particularly in areas with favorable weather conditions, where it causes reduction in quantity and quality of this crop.

Uses of chemicals appear to be the only practical method to control the pathogen at the present moment and thereby to realize the full potential of the crop. During the past years a number of chemicals have been used against the pathogen with varying results. Several chemicals, derivatives of both systemic and non-systemic fungicides and various plant extracts have been studied in vitro and in vivo on both potato and tomato early blight, to find proper fungicides and \or plant extracts with proper rate and proper application time (Ghazanfar et al., 2016; Murmu et al., 2017; Nashwa and Abo-Elyousr, 2012). The majority of these studies focused on A. solani, however few research have been reported on A. alternata as the causal agent of brown spot/early blight of potato (Kapsa, 2009). Inappropriate use of chemicals may lead to serious human health hazards, therefore; concentration of fungicides to a minimum rate, proper application time and intervals are recommended to minimize the adverse impacts on the agro-ecosystem, environment and danger to animals and human consumers.

This work was aim to determine influence of fungicides on the biology of $A$. alternata with a specific observations include the effect of fungicides on spores germination, germ tube growth and linear extension of colony on Agar medium. .

\section{Materials and Methods}

Alternaria alternata was procured from Indian Agricultural Research Institute, New Delhi. Further pure culture was maintained on Potato Dextrose Agar medium (PDA).

\section{Measurement of fungal growth as linear extension on Agar medium}

To evaluate the efficacy three fungicides were taken such as (a) Benomyl or Benlate (Methyl 1-butyl chlorabenzyl-2-benzimidazole carbamate) (b) Blitox-50 (Copper oxychloride) (c) Mancozeb or Dithane M-45 (Zinc ethylene bis dithiocarbamate). A series of fungicides concentrations viz.; 0, 10, 100, 500, 1000 , and 5000 ppm were prepared by incorporating them in PDA medium. $20 \mathrm{ml}$ of each control and treated PDA was dispersed into Petri plates having $90 \mathrm{~mm}$ diameter. Five replicates were maintained for each concentration and control. About 3 hours after the plats were poured; a mycelia disc of $5 \mathrm{~mm}$ diameter taken from the periphery of a 5 days old culture of A. alternata growing on PDA was transferred to the centre of each plate. The plates were incubated at $25^{\circ} \mathrm{C}$ and fungal growth rate was 


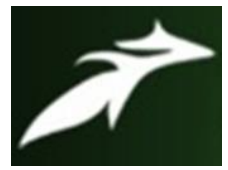

Pramila Tripathi et al, International Journal of Advances in Agricultural Science and Technology, Vol.6 Issue.10, October-2019, pg. 62-71

determined by measuring the diameter of colony at $24 \mathrm{~h}$ intervals. Two measurements at right angle to one another where made each time. Measurements were continued until the fungus had grown up to the periphery of the plate or for a maximum of 7 days.

\section{Spores germination and germ tube elongation}

Fungicides solutions were prepared in distilled water at the concentration of 10, 100, 500, 1000 and $5000 \mathrm{ppm}$. The spores taken from a 5 days old culture were suspended in the above fungicides solutions. From each of the suspension a hanging drop was made on a cavity slide. The cavities we are sealed with Vaseline. Five slides were prepared for each treatment. Slides were incubated in dark at $25^{\circ} \mathrm{C}$ in dark. Observations were taken at the interval of 24,48 and 72 hours. Spores germination and germ tube growth was observed in 10 randomly chosen platforms from each of the slides at a micro scope projection of $10 \times 10$.

\section{Results}

\section{Linear Extension of Fungal Colony on the Agar Medium}

Rate of fungal growth on PDA medium containing fungicides is given in table 1 . All the fungicides inhibited the growth of the fungi and the degree of inhibition increased in proportional to the concentration of the fungicides. Towards the end of the experiment on the benomyl and mancozeb containing medium at the concentration of $10 \mathrm{ppm}$, colony diameter was 75.0 and $81.5 \mathrm{~mm}$, on the other hand at the concentration of $5000 \mathrm{ppm}$ colony growth was totally inhibited in both the treatments. In the copper oxychloride incorporated medium colony developed at the concentration of 10 and 100 ppm, while at 500, 1000 and 5000 ppm colony growth did not occur.

In addition to affecting the rate of colony growth fungicides also promote abnormalities in colony structure, sporulation and spore structure. At the lower concentrations there were no abnormalities in the spore's structure. Therefore for observation of spore abnormalities the highest concentration of treatment in which fungal colony grew was selected. Spores of $A$. alternata growing on untreated PDA had mean length of $27.5 \mu \mathrm{m}$, width $9.5 \mu \mathrm{m}$, number of horizontal septa 5.0 and vertical septa were 3.0 and 2.0 respectively. In copper oxychloride treatment mean length, mean width, mean number of horizontal septa and mean number of vertical septa in spores were $26.25 \mu \mathrm{m}, 10.75 \mu \mathrm{m}, 1.0$ and 2.0 respectively. While in mancozeb treated culture the corresponding values were $14.15 \mu \mathrm{m}, 10.28 \mu \mathrm{m}, 1.0$ and 0.0 . The spore wall in copper oxychloride treated culture became dark black and thicker than the control. 


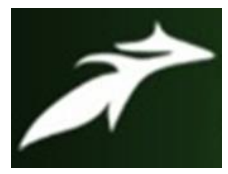

Pramila Tripathi et al, International Journal of Advances in Agricultural Science and Technology, Vol.6 Issue.10, October-2019, pg. 62-71

ISSN: 2348-1358

Impact Factor: 6.057

NAAS Rating: 3.77

\section{Germination of spores}

Table 2 shows the effect of fungicides on the germination of spores. Under control sets that is in the absent of fungicides $100 \%$ spores germination was recorded after 24 hours. All the three fungicides inhibited the spore germination and percentage inhibition increased with increasing concentration of the fungicides. At the interval of 72 hours in $5000 \mathrm{ppm}$ treatment $18.30 \%$ spore germination was recorded in benomyl while at the same concentration in copper oxychloride and mancozeb treatments germination did not occur. After 72 hours at 10, 100, 500 and 1000 ppm concentration of benomyl the germination of spores was 92, 89, 82 and 65 percent respectively. In copper oxychloride after 72 hours at 10,100, 500 and 1000 ppm concentrations the spore germination was 93.7, 91.2, 85.0 and $62.0 \%$ respectively. While in case of mancozeb treatment at the interval of 72 hours the percent germination at different concentrations that is $10,100,500$ and 1000 ppm was 93, 87, 80 and 60\% respectively. Periodic observation of spore germination at the interval of 24 hours showed that a large proportion of spores germinated within 24 hours and only a small proportion germinated during next 48 hours.

\section{Growth of germ tube}

Mean length of germ tube and there elongation rate are given in table 3. Elongation rate of germ tube was generally inhibited by all the fungicides. All the concentration of three fungicides was significantly inhibitory to the growth of germ tube. The degree of inhibition increased with increasing concentration of fungicides. At 10, 100, 500, 1000 and 5000 ppm concentration of benomyl the elongation rate of germ tube was $11,8,3$ and $1.5 \mu \mathrm{m} / \mathrm{h}$ and mean length of germ tube after 72 hour was 801, 570, 372, 201 , and $113 \mu \mathrm{m}$ respectively. At 10,100, 500 and 1000 ppm concentration of copper oxychloride at the end of 72 hours the mean length of germ tube was 763, 469, 332 to and $227 \mu \mathrm{m}$ and the germ tube longest rates were $11,7,5$ and $3 \mu \mathrm{m} / \mathrm{h}$ respectively, while corresponding values in the mancozeb treatments at the same concentrations were 822, 405, 248 and $163 \mu \mathrm{m}$ for the mean length of germ tube and 11, 6, 3 and $2 \mu \mathrm{m} / \mathrm{h}$ for the germ tube elongation rate. At $5000 \mathrm{ppm}$ concentration of copper oxychloride and mancozeb germ tube did not appear.

\section{Discussion}

Results indicate that at 500 to $5000 \mathrm{ppm}$ concentration of the three fungicides colony growth, spore germination as well as germ tube growth was found severely inhibited or at 5000ppm it did not occur. It is well documented that fungicides are toxic against fungi, however toxicity of fungicides varies depending on the chemical formulation of fungicides, species of fungi and also the climatic and other factors at the application site. General tendency of dose dependent decreases in colony growth shows that the inhibition was directly related with quantity of the fungicides. Similar results have been 


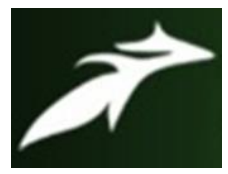

Pramila Tripathi et al, International Journal of Advances in Agricultural Science and Technology, Vol.6 Issue.10, October-2019, pg. 62-71

reported in case of $A$. alternata, Sclerotium rolfsii and phytophthora palmivora using the different fungicides by Sharma and Verma (1985). The three fungicides differed in their effect on the growth of the fungi which was more pronounced at the higher concentration. In general copper fungicides were more toxic than the other two. Mulinge and Griffiths (1974) also observed that copper fungicide was more effective against the coffee rust than benomyl and captafol. A number of other workers have also reported that different fungicides differ in their effect on the growth of fungi.

Results show that the effect of the fungicides on different stages of growth of the fungus varied. In case of all the fungicides the germ tube growth was most adversely affected followed by colony growth and spore germination. Mycelia growth was totally stopped at $5000 \mathrm{ppm}$ of the fungicides, however in case of benomyl $18.3 \%$ of spores could germinate at this consultation. This shows that the actively growing mycelia of $A$. alternata are more severely affected than that of the comparatively thick walled spores. Similar findings have also been reported by Marthur and Sarbhoy (1983) in case of fentin acetate and fantin chloride fungicide; however they did not elaborate their findings. From this result it could be inferred that the fungal propagules found in the form of mycelia are likely to be more severely affected by the fungicides then that of the spores. Tey and Wood (1983) while studying the effect of the fungicides on the Phytophthora palmivora also observed that actively growing mycelia and thin-walled structures like zoospores are more severely affected by the fungicides.

In accordance with the current results, a previous study conducted by Gynoya and Gohel, (2015) reported that systemic fungicides including; tebuconazole, hexaconazole and difenoconazole from the same trizole families have given excellent results of inhibition (\%) of $A$. alternata (causal agent of Chilli leaf spot) at $500 \mathrm{mg} \backslash$ I. Earlier study of Singh and Singh, (2006) screened several fungicides against $A$. alternata and recorded that hexaconazole gave excellent inhibition (\%) of mycelial growth, at a low concentration of $50 \mathrm{mg} \backslash$ I. Gohel and Solanky, (2012) have reported that difenconazole, propiconazole and hexaconazole caused inhibition (\%) of mycelia growth at minimum of $200 \mathrm{mg} \backslash \mathrm{I}$. In addition to $A$. alternata, similar effects of Triazole systemic fungicides were observed on growth inhibition of $A$. solani, the causal agent of tomato early blight, potato early blight, rice blast and other fungal diseases (Gohel and Solanky, 2012; Murmu et al., 2017; Kulmitra et al., 2017; Singh et al., 2018).

In the present study, benomyl a member of the systemic fungicides from Benzimidazoles family was not much effective in inhibiting the mycelial growth and the effects were decreasing in lower concentrations. This result is in line with the study carried out by Gohel and Solanky, (2012). Mancozeb, which is a Dithiocarbamate nonsystemic fungicide with a protective action, caused $100 \%$ mycelial growth inhibition at $5000 \mathrm{ppm}$ after 7 days of incubation In agreement with the current results, an early study of Akbari and Parakhia, (2007) reported that non-systemic fungicides including mancozeb gave 


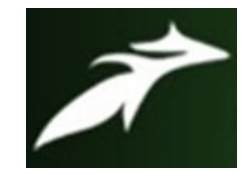

Pramila Tripathi et al, International Journal of Advances in Agricultural Science and Technology,

Vol.6 Issue.10, October-2019, pg. 62-71

ISSN: 2348-1358

Impact Factor: 6.057

NAAS Rating: 3.77

$100 \%$ inhibition of $A$. alternata (causal agent of sesame blight) at minimum concentration of $500 \mathrm{mg} \backslash \mathrm{I}$. Furthermore, Gohel and Solanky, (2012) highlighted that mancozeb at $2000 \mathrm{mg} \backslash$ I caused $100 \%$ inhibition, whereas at $1500 \mathrm{mg} \backslash \mathrm{I}$; it strongly inhibited the mycelial growth by $90.43 \%$.

Copper oxychloride which is a protective wettable fungicide having double effects of systematic and contact fungicide with preventive action was proved to be non-effective on mycelial growth inhibition even at high concentration of $500 \mathrm{ppm}$. In contrast with the present study, Gohel and Solanky, (2012) have reported that copper oxychloride caused $100 \%$ inhibition of mycelial growth and conidial germination at minimum $1000 \mathrm{mg} \backslash \mathrm{l}$, while Kumar et al., (2013) demonstrated that copper oxychloride at concentration of $0.2 \%$; could cause $81.4 \%$ mycelial growth inhibition. Our investigation confirmed that copper oxychloride, at concentration of $500 \mathrm{mg} \backslash$ I $(500 \mathrm{ppm})$ or lower; could not strongly inhibit mycelial growth of $A$. alternata. Copper oxychloride is much more effective in inhibiting conidial germination rather than inhibiting mycelial growth, since copper kills the spores by combining with the sulphahydral groups of certain enzymes. Spores actively accumulate copper and thus germination of these spores is inhibited, even at lower concentrations.

Our future prospectus is to carry out field experiments to explore the effective concentration of the mentioned fungicides under in vivo conditions, and to avoid unnecessary excessive use of the chemical fungicides.

\section{References}

[1] Akbari, L.F., Parakhia, A.M. (2007). Management of Alternaria alternata causing blight of sesame with fungicide. Journal of Mycological Plant Pathology. 37(3): 426-430.

[2] Cromey, M.G., Mulholland, R.I. (1988). Black point of wheat: Fungal associations, cultivar susceptibility, and effects on grain weight and germination. New Zealand Journal of Agricultural Research. 31(1): 51-56.

[3] Ghazanfar, U.M., Raza, W., Ahmed, K.S., Qamar, J., Haider, N., Rasheed, M.H. (2016). Evaluation of different fungicides against Alternaria solani (Ellis \& Martin) Sorauer cause of early blight of tomato under laboratory conditions. International Journal of Zoology Studies. 1(5): 8-12.

[4] Ghazanfar, U.M., Waqas, W., Sahi, S.T., Yasin, S. (2009). Influence of various fungicides on the management of rice blast disease. Mycopathology. 7(1): 29-34

[5] Ginoya, C.M., Gohel, N.M. (2015). Evaluation of newer fungicides against Alternaria alternata (Fr.) Keissler causing fruit rot disease of chilli. International Journal of Plant Protection. 8(1): 169-173. 


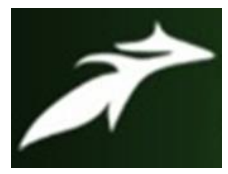

Pramila Tripathi et al, International Journal of Advances in Agricultural Science and Technology, Vol.6 Issue.10, October-2019, pg. 62-71

[6] Gohel, N.M., Solanky, K.U. (2012). In-vitro and In-vivo evaluation of fungicides against Alternaria alternata causing leaf spot and fruit rot disease of chilli. Green Farming. 3(1): 84-86.

[7] Grogan, R.G., Kimble, K.A., Misaghi, I. (1975). A stem canker disease of tomato caused by Alternaria alternata f. sp. lycopersici. Pythpathlogy. 65: 880-886.

[8] Kapsa, J. (2009). Effectiveness of some fungicides in control of Alternaria alternata and Alternaria solani. 11th EuroBlight workshop, Hamar (Norway). PPOSpecial Report. 13: 127-134.

[9] Kulmitra, A.K; Kumar ,V.S; Thejesha, A.G.; Ghosh, A. and Sahu, P. (2017). In vitro evaluation of fungicides against Pyricularia oryzae (Cav.) causing rice blast disease. International Journal of Chemical Studies .5(4): 506-509.

[10] Kumar, M; Bhadauria, V; Singh, K; Singh, C. and Yadav, A.K. (2013). Evaluation of fungicide efficacy for the management of Alternaria leaf spot disease of chilli. Plant Pathology. 12(1): 32-35.

[11] Leiminger, J.H, Hausladen, H. (2012). Early blight control in potato using disease-orientated threshold values. Plant Diseases. 96: 124-130.

[12] Li, J, Mao, L, Zhang, Y, Zhang, L., Jiang, H. (2018). Phytochemical changes in mango fruit in response to Alternaria alternata infection. Czech Journal of Food Science. 36: 227-232.

[13] Mathur, S.B., Sarbhoy, A.K. (1983). Chemical control of Alternaria leaf spot on sugarbeat. Indian Phytopath., 36: 677-679.

[14] Mulinge, S. K., Griffiths, E. (1974) . Effect of fungicides on leaf rust, berry disease foliation and yield of coffee. Trans. Brit. Mycol. Soc., 62:195-507.

[15] Murmu, S.; Dey S., Chakraborty, A. (2017). Efficacy of different fungicides for management of early blight disease of potato. Journal of Applied and Natural Science. 9 (1): 280-285.

[16] Nashwa, S.M.A., Abo-Elyousr, K.A.M. (2012). Evaluation of various plant extracts against the early blight disease of tomato plants under greenhouse and field conditions. Plant Protect. Sci., 48: 7479.

[17] Paurson, E.R, Loit, K, Hansen, M., Tein, B, Williams, I. H., Mänd, M. (2015). Early blight destroys potato foliage in the northern Baltic region. Acta Agriculturae Scandinavica, Section B-Soil and Plant Science. 65(5): 422-432.

[18] Prusky, D, Ben-Arie, R., Guelfat-Reich, S. (1981). Etiology and histology of Alternaria rot persimmon fruits. Phytopathology. 71: 1124-1128.

[19] Sharma, J.P. and Verma, R.N. (1985). Effect of various concentration of fungicides in vitro on Sclerotium state of Corticium rolfsii. Indian Phytopath., 38: 358-360. 


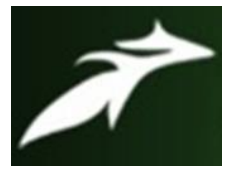

Pramila Tripathi et al, International Journal of Advances in Agricultural Science and Technology, Vol.6 Issue.10, October-2019, pg. 62-71

ISSN: 2348-1358

Impact Factor: 6.057

NAAS Rating: 3.77

[20] Singh, V.P, Khan R.U., Pathak, D. (2018). In vitro evaluation of fungicides, bio-control agents and plant extracts against early blight of tomato caused by Alternaria solani (Ellis and Martin) Jones and Grout. International Journal of Plant Protection. 11(1): 102-108.

[21] Singh, P.C., Singh, D. (2006). In vitro evaluation of fungicides against Alternaria alternata. Annals of Plant Protection Sciences. 14(2): 500-502.

[22] Tey, C.C., Wood, R.K.S. (1983). Effect of fungicides in vitro on Phytophthora pulmivora from cocoa. Trans. Brit. Mycol. Soc., 80: 271-282.

[23] Tsedalye, B. (2014). Review on Early Blight (Alternaria spp.) of Potato Disease and its Management Options. Journal of Biology, Agriculture and Healthcare. 4(27): 191-198.

[24] Tsuge, T., Harimoto, Y., Akimitsu, K., Ohtani, K. Kodama, M., Akagi, Y., Egusa, M., Yamamoto, M., Hiroshi, O. (2011). Host-selective toxins produced by the plant pathogenic fungus Alternaria alternata. Federation of European Microbiological Society. 37: 44-66.

Table 1. Colony diameter $(\mathrm{mm})$ of A. alternata in various concentrations of fungicides $( \pm$ S.E.)

\begin{tabular}{|l|l|l|l|l|l|l|l|}
\hline Fungicides & $\begin{array}{l}\text { Incubation } \\
\text { in days }\end{array}$ & 0 & 10 & 100 & 500 & 1000 & 5000 \\
\cline { 2 - 8 } & 1 & $22.9 \pm 1.50$ & $22.7 \pm 0.50$ & $15.6 \pm 0.50$ & $14.2 \pm 1.50$ & $11.2 \pm 1.50$ & 0.0 \\
\hline \multirow{3}{*}{ Benomyl } & 3 & $45.6 \pm 1.56$ & $38.0 \pm 0.50$ & $30.5 \pm 0.75$ & $26.6 \pm 1.50$ & $20.4 \pm 1.50$ & 0.0 \\
\cline { 2 - 8 } & 5 & $64.8 \pm 2.50$ & $63.5 \pm 1.50$ & $52.4 \pm 1.50$ & $40.2 \pm 2.50$ & $32.7 \pm 1.50$ & 0.0 \\
\cline { 2 - 8 } & 7 & $83.0 \pm 1.66$ & $75.0 \pm 1.70$ & $69.7 \pm 1.50$ & $59.5 \pm 1.50$ & $42.2 \pm 1.50$ & 0.0 \\
\hline \multirow{4}{*}{$\begin{array}{l}\text { Copper } \\
\text { oxychloride }\end{array}$} & 1 & $22.9 \pm 1.00$ & $21.3 \pm 0.50$ & $13.5 \pm 0.50$ & $0.0 \pm 0.00$ & $0.0 \pm 1.50$ & 0.0 \\
\cline { 2 - 8 } & 3 & $45.6 \pm 2.50$ & $37.4 \pm 1.00$ & $26.9 \pm 1.50$ & $0.0 \pm 0.00$ & $0.0 \pm 1.50$ & 0.0 \\
\cline { 2 - 8 } & 5 & $64.8 \pm 2.55$ & $55.5 \pm 1.80$ & $41.1 \pm 1.50$ & $0.0 \pm 0.00$ & $0.0 \pm 1.50$ & 0.0 \\
\cline { 2 - 8 } Mancozeb & 7 & $83.0 \pm 1.80$ & $74.9 \pm 2.50$ & $69.6 \pm 2.50$ & $0.0 \pm 0.00$ & $0.0 \pm 1.50$ & 0.0 \\
\cline { 2 - 8 } & 3 & $22.9 \pm 1.00$ & $21.1 \pm 1.50$ & $17.0 \pm 0.50$ & $13.0 \pm 1.50$ & $6.5 \pm 1.50$ & 0.0 \\
\cline { 2 - 8 } & 5 & $45.6 \pm 1.65$ & $41.3 \pm 1.50$ & $33.4 \pm 1.50$ & $23.4 \pm 1.50$ & $17.7 \pm 1.50$ & 0.0 \\
\cline { 2 - 8 } & 7 & $84.8 \pm 1.60$ & $62.7 \pm 0.50$ & $52.9 \pm 0.50$ & $37.7 \pm 1.50$ & $27.3 \pm 1.50$ & 0.0 \\
\cline { 2 - 8 } & 7 & $81.5 \pm 2.50$ & $71.8 \pm 1.50$ & $54.1 \pm 1.50$ & $35.8 \pm 1.50$ & 0.0 \\
\hline
\end{tabular}




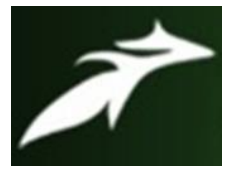

Pramila Tripathi et al, International Journal of Advances in Agricultural Science and Technology, Vol.6 Issue.10, October-2019, pg. 62-71

ISSN: 2348-1358

Impact Factor: 6.057

NAAS Rating: 3.77

Table 2. Percent spores germination of A. alternata in various concentrations of fungicides $( \pm$ S.E. $)$

\begin{tabular}{|l|l|l|l|l|l|l|l|}
\hline Fungicides & Incubation & \multicolumn{7}{|c|}{ Concentrations $(\mathrm{ppm})$} \\
\cline { 2 - 8 } & in hours & 0 & 10 & 100 & 500 & 1000 & 5000 \\
\hline \multirow{3}{*}{ Benomyl } & 24 & $99.4 \pm 1.50$ & $88.0 \pm 2.50$ & $83.2 \pm 1.50$ & $76.0 \pm 1.50$ & $56.0 \pm 1.50$ & $15.2 \pm 0.50$ \\
\cline { 2 - 8 } & 48 & $100 \pm 1.50$ & $89.7 \pm 2.50$ & $84.4 \pm 1.50$ & $79.3 \pm 1.50$ & $61.3 \pm 0.50$ & $16.0 \pm 0.50$ \\
\cline { 2 - 8 } & 72 & $100 \pm 1.50$ & $91.8 \pm 2.50$ & $89.7 \pm 1.50$ & $82.5 \pm 1.50$ & $65.4 \pm 1.50$ & $18.3 \pm 0.50$ \\
\hline \multirow{3}{*}{$\begin{array}{l}\text { Copper } \\
\text { oxychloride }\end{array}$} & 24 & $99.4 \pm 1.50$ & $90.0 \pm 1.50$ & $86.2 \pm 1.50$ & $79.0 \pm 1.50$ & $57.6 \pm 0.50$ & $0.0 \pm 0.00$ \\
\cline { 2 - 8 } & 48 & $100 \pm 1.50$ & $92.0 \pm 1.50$ & $88.4 \pm 1.50$ & $82.5 \pm 1.50$ & $58.5 \pm 1.50$ & $0.0 \pm 0.00$ \\
\cline { 2 - 8 } Mancozeb & 72 & $100 \pm 1.50$ & $93.7 \pm 1.50$ & $91.4 \pm 1.50$ & $85.5 \pm 1.50$ & $61.8 \pm 1.50$ & $0.0 \pm 0.00$ \\
\cline { 2 - 8 } & 24 & $99.4 \pm 1.50$ & $87.7 \pm 1.50$ & $81.3 \pm 1.50$ & $71.1 \pm 1.50$ & $56.5 \pm 0.50$ & $0.0 \pm 0.00$ \\
\cline { 2 - 8 } & 78 & $100 \pm 1.50$ & $90.3 \pm 1.50$ & $86.0 \pm 1.50$ & $76.7 \pm 1.50$ & $59.7 \pm 1.50$ & $0.0 \pm 0.00$ \\
\cline { 2 - 8 } & 72 & $100 \pm 1.50$ & $92.7 \pm 1.50$ & $87.4 \pm 1.50$ & $79.6 \pm 1.50$ & $75.4 \pm 1.50$ & $0.0 \pm 0.00$ \\
\hline
\end{tabular}

Table 3. Germ tube growth $(\mu \mathrm{m})$ of A. alternata in various concentrations of fungicides $( \pm$ S.E. $)$

\begin{tabular}{|l|l|l|l|l|l|l|l|}
\hline Fungicides & $\begin{array}{l}\text { Incubation } \\
\text { in hours }\end{array}$ & 0 & 10 & 100 & 500 & 1000 & 5000 \\
\cline { 2 - 8 } & 24 & $436.1 \pm 2.00$ & $182.1 \pm 3.00$ & $129.4 \pm 1.00$ & $108.3 \pm 2.00$ & $70.0 \pm 0.50$ & $23.5 \pm 0.20$ \\
\cline { 2 - 8 } Benomyl & 48 & $831.5 \pm 3.00$ & $519.5 \pm 2.00$ & $374.6 \pm 2.00$ & $253.0 \pm 2.00$ & $151.6 \pm 0.50$ & $66.1 \pm 0.20$ \\
\cline { 2 - 8 } & 72 & $1675.0 \pm 2.00$ & $801.2 \pm 4.00$ & $569.6 \pm 3.00$ & $371.7 \pm 2.00$ & $200.8 \pm 3.00$ & $112.5 \pm 0.50$ \\
\hline \multirow{3}{*}{$\begin{array}{l}\text { Copper } \\
\text { oxychloride }\end{array}$} & 24 & $436.1 \pm 3.00$ & $399.0 \pm 2.00$ & $271.4 \pm 1.00$ & $185.0 \pm 1.00$ & $94.4 \pm 2.00$ & $0.0 \pm 0.00$ \\
\cline { 2 - 8 } & 48 & $831.5 \pm 5.00$ & $688.6 \pm 5.00$ & $353.9 \pm 1.00$ & $242.0 \pm 1.00$ & $165.0 \pm 1.00$ & $0.0 \pm 0.00$ \\
\cline { 2 - 8 } & 72 & $1675.0 \pm 3.00$ & $763.4 \pm 3.00$ & $469.2 \pm 2.00$ & $332.7 \pm 1.00$ & $227.1 \pm 2.00$ & $0.0 \pm 0.00$ \\
\hline Mancozeb & 24 & $436.1 \pm 4.00$ & $207.3 \pm 2.00$ & $124.8 \pm 0.50$ & $42.3 \pm 0.50$ & $15.4 \pm 0.50$ & $0.0 \pm 0.00$ \\
\cline { 2 - 8 } & 48 & $831.5 \pm 3.00$ & $452.3 \pm 2.00$ & $215.0 \pm 0500$ & $90.8 \pm 0.50$ & $45.2 \pm 0.30$ & $0.0 \pm 0.00$ \\
\cline { 2 - 8 } & 72 & $1675.0 \pm 4.00$ & $821.5 \pm 3.00$ & $405.4 \pm 1.00$ & $247.7 \pm 0.80$ & $163.0 \pm 0.70$ & $0.0 \pm 0.00$ \\
\hline
\end{tabular}




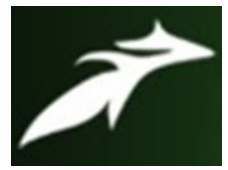

Pramila Tripathi et al, International Journal of Advances in Agricultural Science and Technology, Vol.6 Issue.10, October-2019, pg. 62-71

ISSN: 2348-1358

Impact Factor: 6.057

NAAS Rating: 3.77

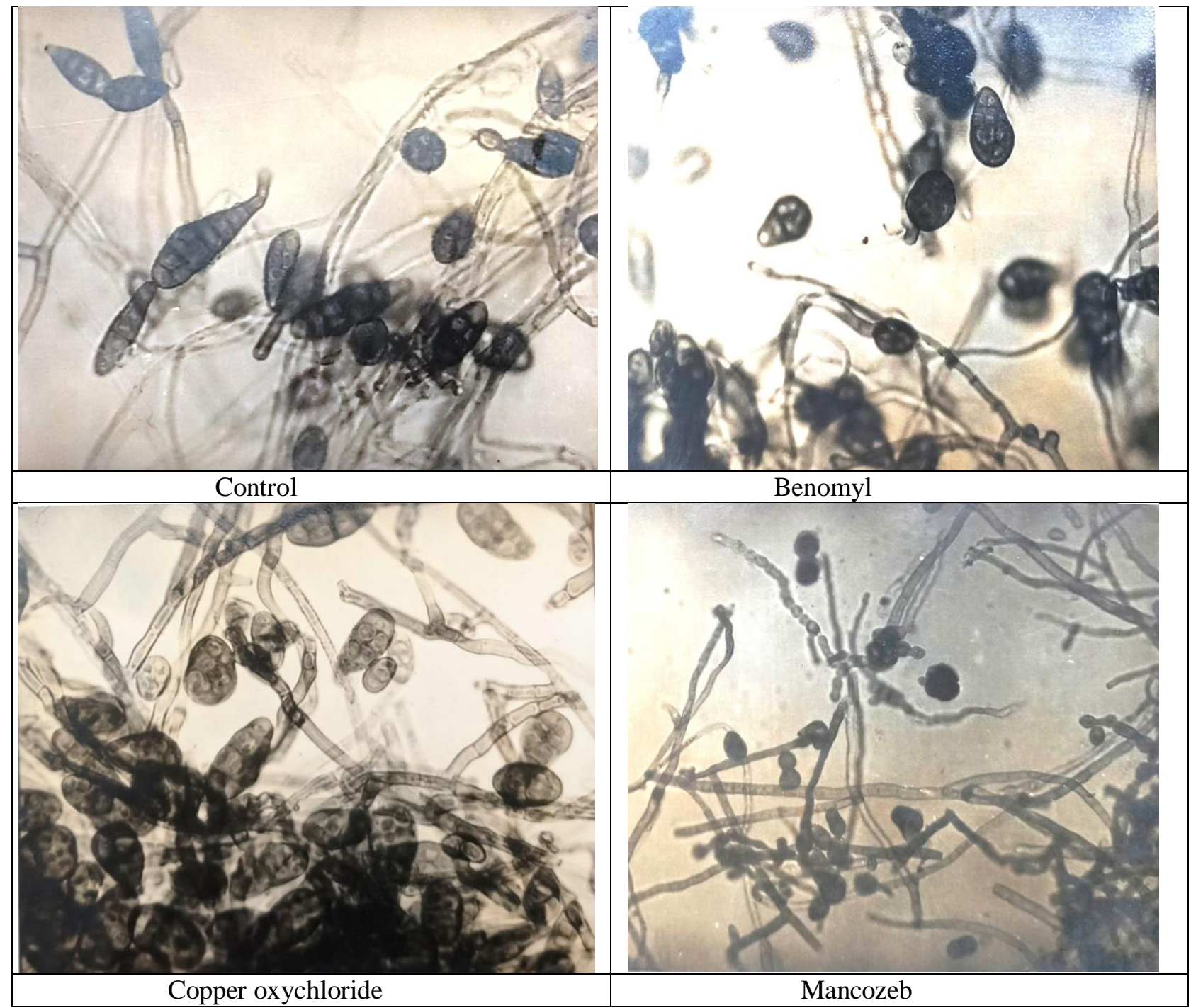

Plate1. Impact of fungicides on the morphology of A. alternata spores 